\title{
Explorative Factor Analysis of K.S. Mishra's Home Environment Inventory
}

\author{
Partha Sarathi Mallik
}

\author{
Department of Education, Fakir Chand College, \\ Diamond Harbour, West Bengal, India
}

\begin{abstract}
The home environment inventory of K.S. Mishra as a tool of measuring psychological interaction between parents and children has 10 variables, i.e. control, protectiveness, punishment, conformity, social isolation, reward, deprivation of privileges, nurturance, rejection and permissiveness by 100 items. In the present study attempt is made to find out latent variables or factors by factor analysis technique by collecting data from 638 higher secondary scheduled caste students. It is found that there are three factors $>1$ eigen value in the inventory which contributes $63 \%$ variance. The factors are named as positive interactive factor, negative interactive factor and disciplinary factor. Nurturance, protectiveness and reward variables are loaded in positive factor; deprivation of privileges, punishment, rejection and social isolation are in negative factor and Conformity, control and permissiveness in disciplinary factor.
\end{abstract}

Keywords: Factor Analysis, Home Environment Inventory

\section{Introduction}

The effect of home environment is concern of researcher due to its multip le effect on socialization, development, readiness for education, motivation, cognitive, emotional development and finally educational achievement (Fantuzzo el al., 2000). The majority research studies found from developing countries including India on home environment as predictor variab le have studied from structural aspect of home environment i.e. Socio-economic status (Obeta, 2014; Asikhia, 2010; Ushie et al., 2012; Escarce , 2003), parental education (Maicibi, 2005; Kundu \& Tutoo, 2000); nature of family (Hill, 2004; Mario, 2006). In comparison to above dimensions research on reciprocal psychological environment, parenting behavior or parental interaction with children is most neglected area of research in India. The attempts made by researchers in Developmental Psychology and Socialization to measure or classify the parental role or parental behavior within family in nu merous ways, realized the fact that development of the child is primarily influenced by the interactive and affectionate home environment and not merely by physical or structural as pect of family (Dornbusch $\&$ Wood, 1989). So the parental behavior is reflected as the psychological family climate that has a significant effect on child development. The positive interactional home environment has the feature like warmth, nurturance, autonomy etc those have positive developmental effect on child (Spiker, Boyce, \& Boyce, 2002; Osofsky \& Thompson, 2000) in general; development of social skills (Calkins, Smith, Gill, \& Johnson, 1998; higher level of adaptation capacity and behavioural functioning (Caspi et al., 2004; Spera, 2005) in particular. Also studies support the argument that negative interactional environ ment like parental critic is $\mathrm{m}$, low warmth, acceptance, hostile behavior are responsible for arousal of behavioural problems (Granic \& Patterson, 2006; Snyder, Stoolmiller, Wilson, \& Yamamoto, 2003; depressive cognitive functioning including self critic ism and low self worth (Garber \& Flynn, 2001; Radke-Yarrow, Belmont, Nottelmann, \& Bottomly, 1990) as cited by Greeberge, J.S, et.al. (2012).

The interactional aspect of home environment is studied by Developmental researchers from parentalchildren interaction, parenting behavior, parental skill, parental attitudes, values, parental discipline techniques etc (Mila, Tuli, 2017) which are different connotative terms used in the research field to indicate how the parents rear the child, why they behave in particular way and what are the factors those determine their value regarding parental behavior.

Though India has a heterogeneous and multi cultural set up but the social life in general and parenting choice, child rearing practice and socialization techniques commonly used by the parents in specific are shaped or influenced by religious and spiritualistic cultural value ingrained in it (Issa, Rita, Annie and Prashant, 2014, Uma, D. Krishnan, 2004). Majority are Hindus who discharge their social responsibility as per vedic, Upanishad and Purana value system. According to Uma D. Krishna, 2004 "the Hindu ethics defines clearly about the code of 
conduct, relational behavior and socializing goal". As a parent their parental values, attitudes and behavior are shaped and guided by religious values i.e. (I) respect for seniors or aged people without arguments, i.e. high value for obedience or conformity and control (Sala, 2002); (II) caste or clan based social identity i.e. Socio-economic behavior (III) Control, protection and care are simu ltaneously exhibited; (IV) Differential treatment for son and boys as boys will perform ritualistic family or clan related responsibility and will take care during their old age whereas after marriage daughter will go to in-law house and will lose their parental or family identity, i.e. there is a clear role differentiation, delineating expectations and type of interaction in families based on gender (IV) The family system is patriarchal, patrilineal, and patrilocal (Sheth, 1995), (V) Interdependence, group solidarity, personal humiliation in Asian subcontinent (Wang \& Leichtman, 2000). So at a nut sell it can be told that the parenting behavior of Indian parents are shaped according to the culturally acceptable religious and spiritual value system which reflects their family environ ment.

\section{Approaches for studying psycho- interactional within home environment}

Researchers aim at exploring the parenting styles/parental practice/parent-child psychological interaction collect data from three sources (I) survey answers from parents ( e.g. Solantaus et.ala., 2004); (II) self reports from children and adolescents (e.g. Wen and Hui 2012; Steinberg et al.1991; Steinberg 2001); (III) self observations (Baumrind 1971,1978,2013) as mentioned by Jon Ivar Elstad $\&$ Kari Stefansen, 2014. Though the last approach is more beneficial as it actually reflects the reciprocal relation between parents and child but this approach requires more number of data (Chen and berden, 2006). Assessing parenting style or practice from parents perceptive though is beneficial for children or teenaged but it has also some limitation as parents do not always perceive adolescents' feeling in accurate way (Ben-Ariech, 2008) and they have been found to be more bothered about negative interactions and minor conflicts (Steinberge and Steinberg, 1994) and parents own perception about interaction is generally guided by social conformity wishes. (Jon Ivar Elstad \& Kari Stefansen, 2014). But in the other hand children and adolescents own experience regarding parenting styles and interaction gives the real picture about existing parenting behavior with in family they are the receiver and acute observer (Casas, 2011). As a results lots of empirical studies on parenting styles or practices are found where data are collected from receiptants point of view (e.g. Jonsson and Ostberg, 2010; Sandbaek,

\section{ISS N 2455-6378}

2009). So in the present study attempt is made to explore parenting behavior within scheduled caste family in West Bengal, India by collecting data from children perspective.

\section{Parent-Child interaction measure ment tools:}

To measure the parent-child interaction with home environment, although hugh number of tools are available in western world either in the form of parenting scale, parenting behavior scale, but in case of Indian context there is a few tools available those can be used for assessing parent child-interaction like parent-child relation scale of Rao (1989) which is an adapted from Roe-Seigalman's parent-child relationship questionnaire and this scale has 100 items to measure 10 dimensions like protecting, symbolic, punishment, rejecting, object punishment, demanding, indifferent, symbolic reward, loving, object reward and neglecting; G. P. Sherry and J. C. Sinha's Family Relationship Inventory which has 150 items from three major variables (I)Provides acceptance, (II) avoidance (III). Concentration; N. S. Chauhan

and Harish Sharma Parent Child Relationship Scale which has only 8 items to be responded by parents; N. S. Chauhan and C. P. Khokhar's Multi Dimensional. Parenting Scale which has 56 items from 7 dichotomous dimensions of parenting like hate-love, discouragement-encouragement, rejection-acceptance, dependence-independence, autocratism- emocratism, submission-dominance, conservatism-progressivism; Parenting Style Scale of Madhu Gupta and Dimple Mehtani which has 44 items from four parenting styles democratic, Autocratic, Permissive, Uninvolved; Parenting Scale of R. L. Bharad waj which has 40 items to measure 8 dichotomous mode of parenting like rejection vs. acceptance, II. carelessness vs. protection, neglect vs. indulgence, utopian expectations vs. realism, lenient standard vs. moralis $m$, freedom vs. discipline, faulty role expectations vs. realistic role expectations, and marital conflict vs. marital adjustment; Three Dimensional Parental Behaviour Inventory of

Hardeo Ojha which has 48 items; Children's Perception of Parenting Scale of Anand Pyari and Raj Kumari Kalra which has 44 items from six dimensions of parenting like Democratic, Autocratic, Accepting, Rejecting, Over projecting, Over demanding; Parental Involvement Scale of Vijaya Laxmi Chauhan and Gunjan Ganotra Arora which has 25 items from three aspects of involvements like connection, monitoring and psychological autonomy; Parental Involvement Scale of Rita Chopra and Surabala Sahoo which has 34 items from dimensions of involvements like School Involvement, Home Involvement and Involvement Through PTA; Parental Disciplinary Practice 
Inventory of Jyoti Mankar which has 20 items; home environment inventory of Prerana Mohite that has 24 items from 5 sub tests like language stimulation, physical environment, encouragement of social maturity, variety of stimulation and maternal attitude and disciplining; Home Environment Scale of Reena Sharma and Vibha Nigam which has 84 items from five areasAcceptance, Autocratic, Over projection, Permissiveness and Rejection; Home Environment Scale of A. Akhtar and S. B. Saxena which has 50 items from 10 area like Protectiveness, II. Parental involvement, Academic stimulation, Rewards, Parental Warmth, Punishment, Participation in home affairs, Control, Permissiveness, Parental expectation; Family Environment Scale of Harpreet Bhatia and N. K. Chadha which has 69 items from eight sub-scales - cohesion, expressiveness, conflict, acceptance caring (Relationship dimensions), independence, active recreational orientation (personal growth dimension), organization and control ; Family Environment Scale of Shaloo Saini and Parminder Kaur whch has 45 items from 9 dimensions like Communication, Encouragement of the Individuals, Commitment to Family, Religious Orientation, Social Connectedness, Ability to Adopt, Expressing Appreciation, Clear Roles, Time spent together; Family Climate Scale of Beena Shah which has 90 items from ten dimensions - freedomrestrictiveness, attention-negligence, dominancesubmission, acceptance-rejection, trust-distrust, indulgence- avoidance, warmth-coldness, expectation hopelessness, partiality-fairness, open communication-controlled communication; home environment inventory of K.S. Mishra which has 100 items from 10 categories of parent-child interaction like control, protectiveness, punishment, conformity, social isolation, reward, deprivation of privileges, nurturance, rejection and permissiveness. The maximum available tools to measure psychological interaction between parents and children which is known as psychological home environment where the different types variables taken to include items for the scale.

\section{Factor Analysis and Principal component analysis:}

During research researchers collect data and try to elic it results based upon the variables as mentioned in the tools. But from variable wise results, some time we face problem to get holistic idea about particular phenomenon because sometimes some variables seem to be homogeneous or similar in nature or as a researcher we want to know what are the primary factors those controls or influence the variables or structure of a set of latent variables. At that time we want to reduce the data set to a
ISS N 2455-6378

more manageable size while retaining as much of the original information as possible. In this situation the statistical techniques to be used is factor analysis. The factor analysis or principal component analysis aim to reduce set of variables to smaller set of dimensions called factors in factor analysis and components in Principal component analysis. Factor Analysis tries to achieve parsimony by explaining the maximum amount of common variance in correlation matrix using smallest number of explanatory constructs (Field, A, 2013).

In the present paper an attempt is made to explore factors as measured by 10 variables with the help of 100 items by K.S. Mishra's Home environment inventory. As there are 100 items in the scale that measures 10 variables an attempt is made to find out the cluster variables and latent variable under laying in the scale for ease interpretation of data.

\section{Methods}

\subsection{Participants}

In the present study the sampling design chosen by researcher is stratified area sampling. At first from the total districts of West Bengal two districts were selected randomly to represent rural and urban population. South $24 \mathrm{pgs}$ district was selected as rural one and Kolkata was selected to represent urban area. 15 Co-Education Higher Secondary schools in South 24 pgs 15 schools were selected and from Kolkata district 14 schools were selected randomly. All the Scheduled caste students from these schools constitute the sample. The sample comprised four strata on the basis of Location-South 24 pgs schools as Rural and Kolkata as Urban) and Gender (Boys and Girls). N = 638 .

\section{Sample Demographics as number and percentage}

\begin{tabular}{lccc} 
Demography & Level & $\mathbf{n}$ & Percentage \\
\hline & & & \\
$\begin{array}{l}\text { Gender } \\
\text { \& }\end{array}$ & & \\
Locality Urban Boy Girls & 155 & $24.29 \%$ \\
& 166 & $26.01 \%$ \\
Rural Boys & 153 & $23.98 \%$ \\
& & \\
Urban Girls & 164 & $25.70 \%$
\end{tabular}

\subsection{Scale Description:}

The perception of SC students towards parental interactions or behaviour which reflects their home environ ment is measured by culturally adapted Home environment Inventory (HEI) originally developed by K.S. Mishra. Before use the standardized tool was culturally adapted on Bengali 
speaking higher secondary students by maintaining procedural mechanism of appropriate translation, psychometric property estimation and a pilot study was conducted on 100 sample (50 boys, 50 girls 50 rural and 50 urban). The inventory had 100 items meant to measure 10 variables i.e. A- Control, BProtectiveness, C- Punishment, D-Conformity, ESocial Isolation, F-Reward, G-Deprivation of privileges, H-Nurturance, I-Rejection and JPermissiveness.

Control variable indicates about autocratic behavior of the parents within family where various types of restrictions are imposed on child to discipline them. Protectiveness implies excessive care and cautious taken by parents for prevention of independent activities including dangerous and risky ones. Punishment indicates the harsh behaviors in the form of physical and psychological torture as consequence of undesirable behavior. Conformity indicates parental direction, command or order with which the child is expected to comply by action. Social isolation variable is concerned with use of isolation from beloved persons except family members for negative actions. The reward variable indicates use of material as well as symbolic rewards to strengthen or increase or increase probability of desirable behaviors. Deprivation of privileges implies controlling children's undesirable behavior by depriving love, respect and care from parents. Nurturance indicates use of unconditional physical and emotional attachment or actions for growth or progress of children. Rejection implies ever action, feelings or thought of children are rejected that means children are not allowed to express their independent feelings, behavior to become an autonomous individual. Permissiveness means provision of opportunities to child to express their views freely and act accordingly (Mishra, K.S).

The response are measured by summated ratings in Likert scale. During adaptation for Bengali speaking population the content aspect of validity is maintained and the reliability coefficients of different subscales are estimated by Cronbach's $\alpha$ formula. The reliability coefficients for dimensions A-.963, B-.902, C-.887, D-.861, E-.849, F-.755, G768, H-815, I- .826, J-738 respectively. This section must contain specific details about the materials studied, instruments used, specialized chemicals source and related experimental details which allow other research worker to reproduce the results. The journal will not be held responsible if any kind of plagiarism followed and the editor's decision would be final if any litigation arises during processing or after publishing.

6. Results: From the descriptive analysis it is found that the mean of students perception in Control

\section{ISS N 2455-6378}

dimension is 19.67 ; protective dimension is 24.53 ;punishment dimension is 22.17 : conformity is 29.89 : social isolation is 7.34 : reward dimension is 28.39 : deprivation of privilege is 7.52 : nurturance is 23.58: rejection is 11.27 and permissiveness dimension is 18.66 . Prior to conducting exploratory factor analysis, the suitability of the data was assessed. Inspection of the correlation matrix showed many coefficients of 0.35 or more. A Kaiser-Meyer Oklin value greater than 0.5 indicates sampling adequacy which was supported in this analysis $(\mathrm{KMO}=0.678)$. The Bartlett's Test of Sphericity (testing a null hypothesis that variables are completely uncorrelated) was significant $(p<.05)$ supporting the factorability of the correlation matrix (Tabachnik B, Fidell LS, 2001)

The Principal axis factor analys is revealed that there are 3 factors having eigen value more than 1 accounts for $63 \%$ variance, also an inspection of the scree plot suggested there was a clear plateau after three factors. First factor $(27.17 \%)$, second factor and third factor $(22.16 \%)$, third factor $(13.16 \%)$ and after varimax rotation the variance contributed by first, second and third are $26.88 \%, 18.20 \%$ and $17.91 \%$ respectively. In terms of rotated component matrix result the variable named deprivation of privileges, punishment, rejection and social isolation loading on factor 1 are $.922, .689, .676$ and .924 respectively which is named as Negative interactive behavior; nurturance, protectiveness and reward variables loading on factor 2 are $.800, .686, .822$ respectively named as Positive interactive behaviour; Conformity, control and permissiveness variables loads 769, 791, 641 on factor 3 and named as Discip linary Interactive behavior.

Table 1: Descriptive Statistics

\begin{tabular}{|l|r|r|r|}
\hline & \multicolumn{1}{|c|}{ Mean } & $\begin{array}{c}\text { Std. } \\
\text { Deviation }\end{array}$ & $\begin{array}{c}\text { Analysis } \\
\text { NentROL }\end{array}$ \\
\hline CONTR. & 5.390 & 638 \\
PROTECTIVE & 24.53 & 4.670 & 638 \\
PUNISHMENT & 22.17 & 4.210 & 638 \\
CONFORMITY & 22.89 & 5.630 & 638 \\
SOCIAL & 7.34 & 4.320 & 638 \\
ISOLATION & & & \\
\hline REWARD & 28.39 & 5.110 & 638 \\
DEPRIVATION OF & 7.52 & 4.070 & 638 \\
PRIVILIGE & 23.58 & 5.470 & 638 \\
NURURANCE & 11.27 & 4.130 & 638 \\
REJECTON & 18.66 & 5.820 & 638 \\
PERMISSIVE & & & \\
\hline
\end{tabular}


KMO and Bartlett's Test

\begin{tabular}{|ll|r|}
\hline $\begin{array}{l}\text { Kaiser-Meyer-Olkin Measure of } \\
\text { Sampling Adequacy. }\end{array}$ & .678 \\
$\begin{array}{l}\text { Bartlett's Test of } \\
\text { Sphericity }\end{array}$ & $\begin{array}{l}\text { Approx. } \\
\text { Chi- } \\
\text { Square }\end{array}$ & 2436.664 \\
& df & 45 \\
& Sig. & 0.000 \\
\hline
\end{tabular}

Total Variance Explained

\begin{tabular}{|c|c|c|c|c|c|c|c|c|c|}
\hline \multirow[b]{2}{*}{ Component } & \multicolumn{3}{|c|}{ Initial Eigenvalues } & \multicolumn{3}{|c|}{$\begin{array}{c}\text { Extraction Sums of Squared } \\
\text { Loadings }\end{array}$} & \multicolumn{3}{|c|}{$\begin{array}{l}\text { Rotation Sums of Squared } \\
\text { Loadings }\end{array}$} \\
\hline & Total & $\begin{array}{c}\% \text { of } \\
\text { Variance }\end{array}$ & $\begin{array}{c}\text { Cumulative } \\
\%\end{array}$ & Total & $\begin{array}{c}\% \text { of } \\
\text { Variance }\end{array}$ & $\begin{array}{l}\text { Cumulative } \\
\%\end{array}$ & Total & $\begin{array}{c}\% \text { of } \\
\text { Variance }\end{array}$ & $\begin{array}{c}\text { Cumulative } \\
\%\end{array}$ \\
\hline 1 & 2.768 & 27.679 & 27.679 & 2.768 & 27.679 & 27.679 & 2.688 & 26.884 & 26.884 \\
\hline 2 & 2.216 & 22.162 & 49.842 & 2.216 & 22.162 & 49.842 & 1.820 & 18.203 & 45.087 \\
\hline 3 & 1.316 & 13.164 & 63.006 & 1.316 & 13.164 & 63.006 & 1.792 & 17.919 & 63.006 \\
\hline 4 & .905 & 9.052 & 72.058 & & & & & & \\
\hline 5 & .745 & 7.450 & 79.507 & & & & & & \\
\hline 6 & .569 & 5.694 & 85.201 & & & & & & \\
\hline 7 & .554 & 5.535 & 90.737 & & & & & & \\
\hline 8 & .472 & 4.715 & 95.452 & & & & & & \\
\hline 9 & .387 & 3.869 & 99.321 & & & & & & \\
\hline 10 & .068 & .679 & 100.000 & & & & & & \\
\hline
\end{tabular}

Extraction Method: Principal Component Analysis.

\begin{tabular}{|l|r|r|r|}
\multicolumn{4}{|c|}{ Component Matrix } \\
\hline & \multicolumn{3}{|c|}{ Component } \\
\cline { 2 - 4 } & \multicolumn{1}{|c|}{1} & \multicolumn{1}{|c|}{2} & \multicolumn{1}{c|}{3} \\
\hline CONFORMITY & -0.343 & 0.474 & 0.515 \\
CONTROL & -0.186 & 0.583 & 0.513 \\
PERMISSIVENESS & -0.233 & 0.49 & 0.373 \\
NURTURANCE & -0.066 & 0.567 & -0.575 \\
PROTECTIVENESS & -0.362 & 0.642 & -0.232 \\
REWARD & -0.326 & 0.601 & -0.484 \\
DEPRIVATION OF & 0.859 & 0.338 & -0.01 \\
PREVILEGE & & & \\
PUNISHMENT & 0.622 & 0.28 & 0.171 \\
REJECTON & 0.663 & 0.171 & -0.044 \\
SOCIAL ISOLATION & 0.872 & 0.308 & 0.008 \\
\hline EXtraction Method: Principal Component Analysis.
\end{tabular}

a. 3 components extracted.
Rotated Component Matrix

\begin{tabular}{|l|r|r|r|}
\hline \multirow{2}{*}{} & \multicolumn{3}{|c|}{ Component } \\
\cline { 2 - 4 } & \multicolumn{1}{|c|}{1} & \multicolumn{1}{|c|}{2} & \multicolumn{1}{c|}{3} \\
\hline CONFORMITY & -.118 & .052 & .769 \\
CONTROL & .068 & .090 & .791 \\
PERMISSIVENESS & -.008 & .131 & .641 \\
NURTURANCE & .123 & .800 & -.041 \\
PROTECTIVENESS & -107.000 & .686 & .340 \\
REWARD & -.101 & .822 & .122 \\
DEPRIVATION OF & .922 & .032 & -.043 \\
PREVILEGE & & & \\
PUNISHMENT & .689 & -.076 & .121 \\
REJECTON & .676 & -.012 & -.116 \\
SOCIAL ISOLATION & .924 & -.005 & -.052 \\
\hline
\end{tabular}

Extraction Method: Principal Component Analysis. Rotation Method: Varimax with Kaiser Normalization.

a. Rotation converged in 5 iterations. 


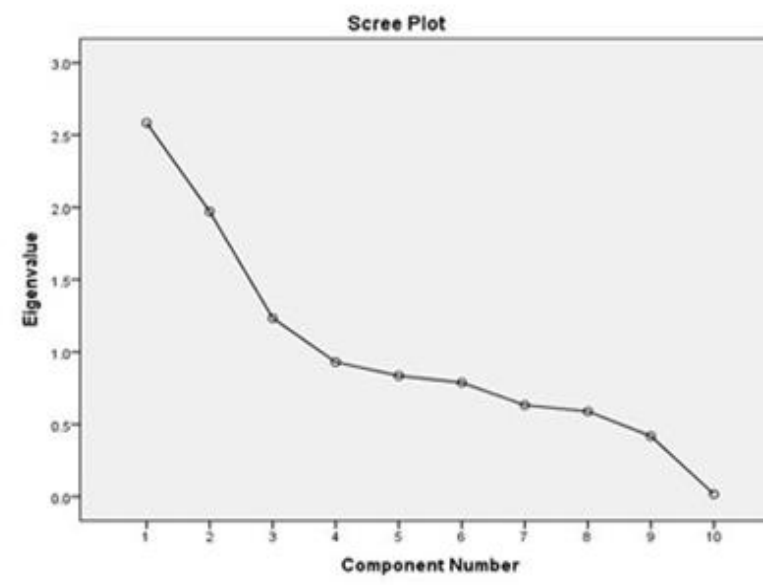

\section{Conclusion:}

The exploration of three factors (positive, negative and disciplinary ) within the home environment inventory having Eigen value more than 1 which they cumulatively contribute $63 \%$ variance. Also graphically the scree plots indicates three factors in the scale. So finding out factors or latent variables in this HEI will help a lot for the researcher who are interested in nature of home environment for any population.

\section{References :}

[1] Asikhia O.A. (2010)."Students and teachers' perception of the causes of poor academic performance in Ogun state secondary schools [Nigeria]: implications for counselling for national development". European J. Social Sci., 13,229-249.

[2] Barcellos , Silvia H., Leandro Carvalho, and Adriana Lleras -Muney. (2014). "Child Gender and Parental Investments in India: Are Boys and Girls Treated Differently?" American Economic Journal: Applied Economics 6(1): 157-89.

[3] Bhalotra, Sonia, Christine Valente, and Arthur V.Soest. (2010). "The Puzzle of Muslim Advantagein Child Survival in India."Journal of Health Economics 29(2):191-204.

[4] Borooah , Vani K. and Sriyalyer. (2005). "Vidya, Veda, and Varna: The Influence of Religion and Caste on Education in Rural India."Journal of Development Studies 41(8):1369-1404.
ISSN 2455-6378

[5] Caspi A, Moffitt TE, Morgan J, Rutter M, Taylor A, Arseneault L, Polo-Tomas M.(2004). Maternal expressed emotion predicts children's antisocial behavior problems: Using monozygotic-twin diffe rences to identify environ mental effects on behavioral development. Develop mental Psychology. 40:149-161.

[6] Catalog of Psychological tests. National Psychological Corporations, Allahabad. Retrieved from http://www.npcindia.co m/downloads/NPCCatalouge-2017.pdf

[7] Das Gupta, Monica. (1987). "Selective Discrimination against Female Children in Rural Punjab, India.'Population and Development Review 13(1):77-100.

[8] Dornbusch, S. M., \& Wood, K. D. (1989). Family processes and educational achievement.In W. J. Weston (Ed.), Education and the American Family (pp. 66-95). New York: New York University Press

[9] Escarce, J.J. (2003). Socio-economic status and the fates of adolescents.Health Serv. Res., 38, 1229-1234.

[10] Fantuzzo, J., Tighe, E., \& Childs, S. (2000). Family Involvement Questionnaire: A multivariate assessment of family participation in early childhood education. Journal of Educational Psychology 92, 367376.

[11] Fausto-Sterling, A., Coll, C. G., \& Lamarre, M. (2012). Sexing the baby: Part 2 applying dynamic systems theory to the emergences of sex-related differences in infants and toddlers. Social Science \& Medicine, 74, 1693-1702.

doi:10.1016/j.socscimed.2011.06.027

[12] Field, A, (2013). Discovering Statistics using IBM SPSS Statistics. Sage Publication India Pvt Ltd, New Delhi.

[13] Forry ND, Tout K, Rothenberg L, Sandstrom H, Vesely C.(2013) Child Care Decision-Making Literature Review. Washington, DC: Office of Planning, Research and Evaluation, Administration for Children and Families, U.S. Department of Health and Human Services; (OPRE Brief 2013-45). 
[14] Granic I, Patterson GR.(2006) Toward a comprehensive model of antisocial development: A dynamic systems approach. Psychological Review ; 113:101131.10.1037/0033-295X.113.1.101

[15] Greenberg JS, Seltzer MM, Baker JK, et al.(2012). "Family Environment and Behavior Problems in Children, Adolescents, and Adults with Fragile X Syndrome". American journal on intellectual and developmental disabilities. 117(4):331-346. doi:10.1352/1944-7558117.4.331.

[16] Hill N.E., Castelino O.R., Lansford J.E., Nowlin E., Dodge P., Bates K.A., Pettit G.S. (2004). "Parent's Academic Involvement as Related to School Behavior, Achievement and aspirations: Demographic Variations across Adolescence". Child development, Vol. 75 (5), pp.1491-1509

[17] Isaac Rita , I. K. Annie, and H. R. Prashanth. (2014). Parenting in India. H.Selin (ed.). Parenting across culture: Child rearing, Motherhood and Fatherhood in Non-Western Culture, Science Across culture: The History of Non-Western Science \&. DOI 10.1007/978-94-007-9_4

[18] Jon Ivar Elstad \&Kari Stefansen (2014). "Social Variations in Perceived Parenting Styles among Norwegian Adolescents". Child Ind Res 7:649-670. DOI 10.1007/s 12187-014-9239-5

[19] Kundu, C.L. \&Tutoo, D.N. (2000).Educational psychology. New Delhi: Sterling Publishers

[20] Steinberg, L., \& Steinberg, W. (1994). Crossing paths: How your child's adolescence triggers your own crisis. New York: Simon \& Schuster.

[21] Sutker P. Drug and Psychopathology. Maryland: National Institute of Drug Abuse Research. 1977; 19:23-8

[22] Wang, W. \& Leichtman, M.D. (2000). "Same beginnings, different stories: A comparison of American and Chinese children's narratives". Child development, $71,1329-1346$

\section{ISS N 2455-6378}

[23] Maicibi, N.A. (2005). Pertinent issues in management: human resource and educational management. Kampala: Net Media Publishers.

[24] Mario C. D. (2006).”The Effect of Parent Absent on Children", Child Study Journal , Vol. 6 (2), p. 165.

[25] Obeta, Anthonia O (2014). "Home environmental factors affecting students' academic performance in Abia State, Nigeria". Jelgava, 7 - 8.retrived fromhttp://lufb.llu.lv/conference/REEP/2014/La tvia-Univ-Agricult-REEP-2014proceedings141-149.pdf

[26] Osofsy, JD.; Thompson, MD. Adaptive and maladaptive parenting: Perspectives on risk and protective factors. In: Shonkoff, JP.; Meisels, SJ., editors. Handbook of early childhood intervention. 2. New York, NY: Cambridge University Press; 2000. p. 5475.

[27] Rafferty Y.(2013). "International dimensions of discrimination and violence against girls: A human rights perspective". Journal of International Women's Studies. ;14:1-23.

[28] Sala, M. J. (2002). The conflict between collectivism and individualism in adolescent development: Asian Indian female decision making in regard to cultural normative behavior. Doctoral dissertation, Loyola University of Chicago

[29] Snyder J, Stoolmiller M, Wilson M, Yamamoto M.(2003). "Child anger regulation, parental responses to children's anger displays, and early child antisocial behaviour". Social Development; 12:335360

[30] Spiker, D.; Boyce, GC.; Boyce, LK.(2002). "Parent-child interactions when young children have disabilities". In: Glidden, LM., editor. International review of research in mental retardation. Vol. 25. SanDiego, CA: Academic Press; 2002. p. 35-70.

[31] Spera C(2005). "A review of the relationship among parenting practices, parenting styles, and adolescent school achievement". Educational Psychology Review. 2005; 17:125-146 
[32] Tuli M.(2012). "Beliefs on parenting and childhood in India". Journal of Comparative Family Studies ;43(1):81-91.

[33] Uma D. Krishnan, M.S (2004). parentadolescent conflict and adolescent functioning in a collectivist, ethnically heterogeneous culture: Malaysia, Ph.D. thesis submitted to University of Ohio. Retrieved from. https://etd.ohiolink.edu/!etd.send_file?acces sion $=0$ su $1079038747 \& \mathrm{~d}$ is position $=$ in line

\section{ISSN 2455-6378}

[34] Ushie, M.A., Onongha, G.I., Owolabi, E.O. \&Emeka, J.O. (2012). Influence of family structure on students academic performance in Agegelocal government area, Lagos State, Nigeria.Eu ropean J. Educ. Studies, 4, 177-187.

[35] Varma VK. Social disadvantage, Mental Health and Social Justice. In: Varma VK, editor. Culture, Personality and Mental Illness. New Delhi: Jaypee Brothers Medical Pub lishers; 2009

[36] Wickstrom, A. (2010). Influencing gender relations through child parent relationship therapy. International Journal of Play Therapy, 19(2), 79-94. doi:10.1037/a00 